\title{
The Border Environmental Health Initiative-Investigating the Transboundary Santa Cruz Watershed
}

In 2004 the U.S. Geological Survey (USGS) launched the Border Environmental Health Initiative (BEHI), a major project encompassing the entire U.S.-Mexico border region. In 2009, a study of the Santa Cruz River Watershed (SCW), located in the border region of Arizona and Sonora, Mexico, was initiated as part of the BEHI. In this borderland region of the desert Southwest, human health and the ecosystems on which humans rely depend critically on limited water resources. Surface water is scarce during much of the year, and groundwater is the primary source for industrial, agricultural, and domestic use.

In order to identify risks to water resources in the SCW, and the potential consequences to riparian ecosystems and ultimately human health, the USGS is using an interdisciplinary and integrative approach that incorporates the expertise of geographers, hydrologists, biologists, and geologists to track organic and inorganic contaminants and their effects from sources to sinks in sediment, water, plants, and animals. Existing groundwater and surfacewater models are being used and modified to assess contaminant and sediment transport. Water samples, as well as samples of sediment, aquatic macroinvertebrates, aquatic plants (macrophytes), algae, riparian grasses, fish, and birds have been and will continue to be sampled at five locations along the Santa Cruz River (fig. 1).

Figure 1. U.S. Geological Survey scientists taking samples of $(A)$ plants and soil, $(B)$ water and aquatic invertebrates, and $(C)$ environmental parameters in the Santa Cruz River watershed.
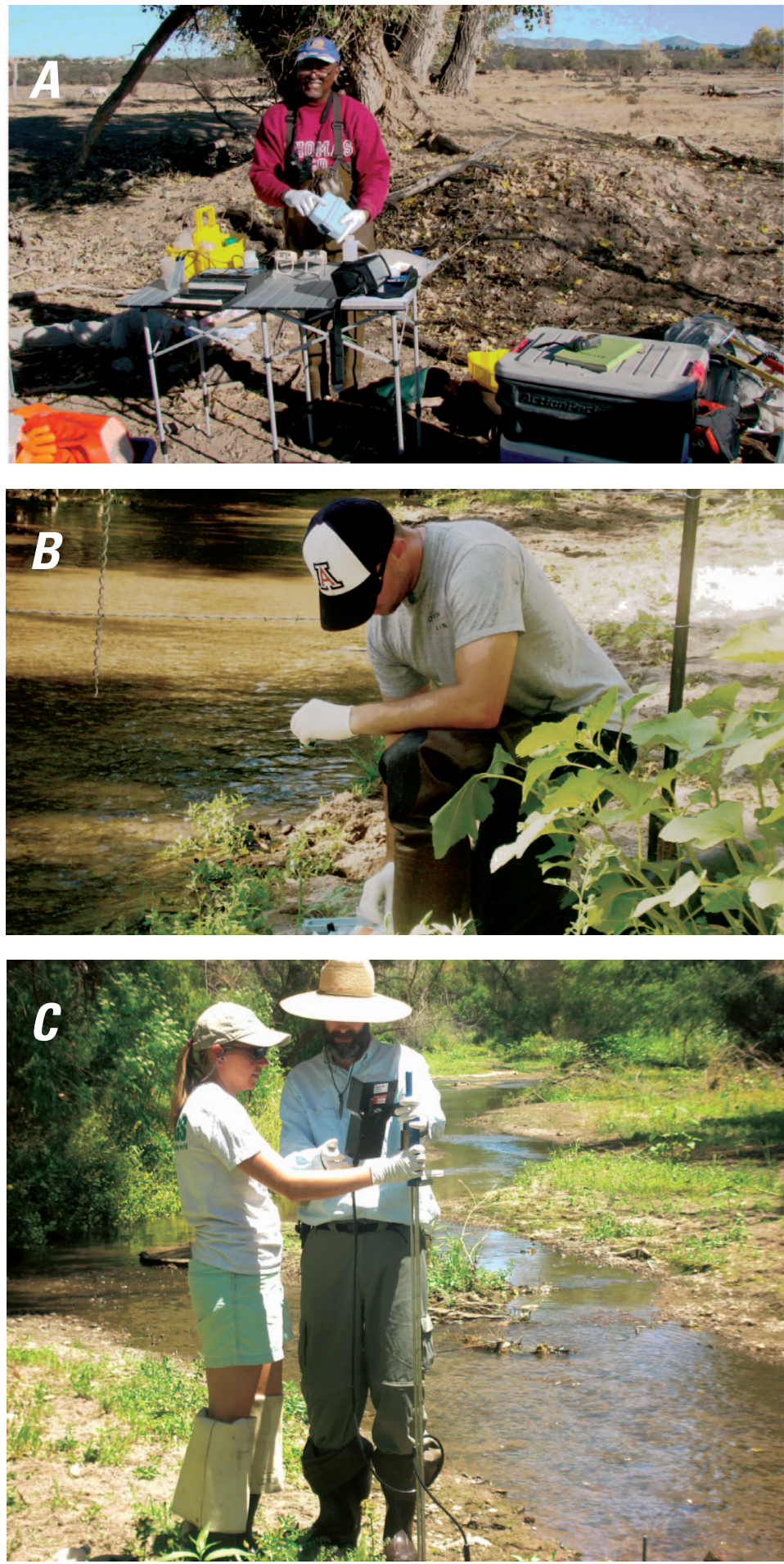


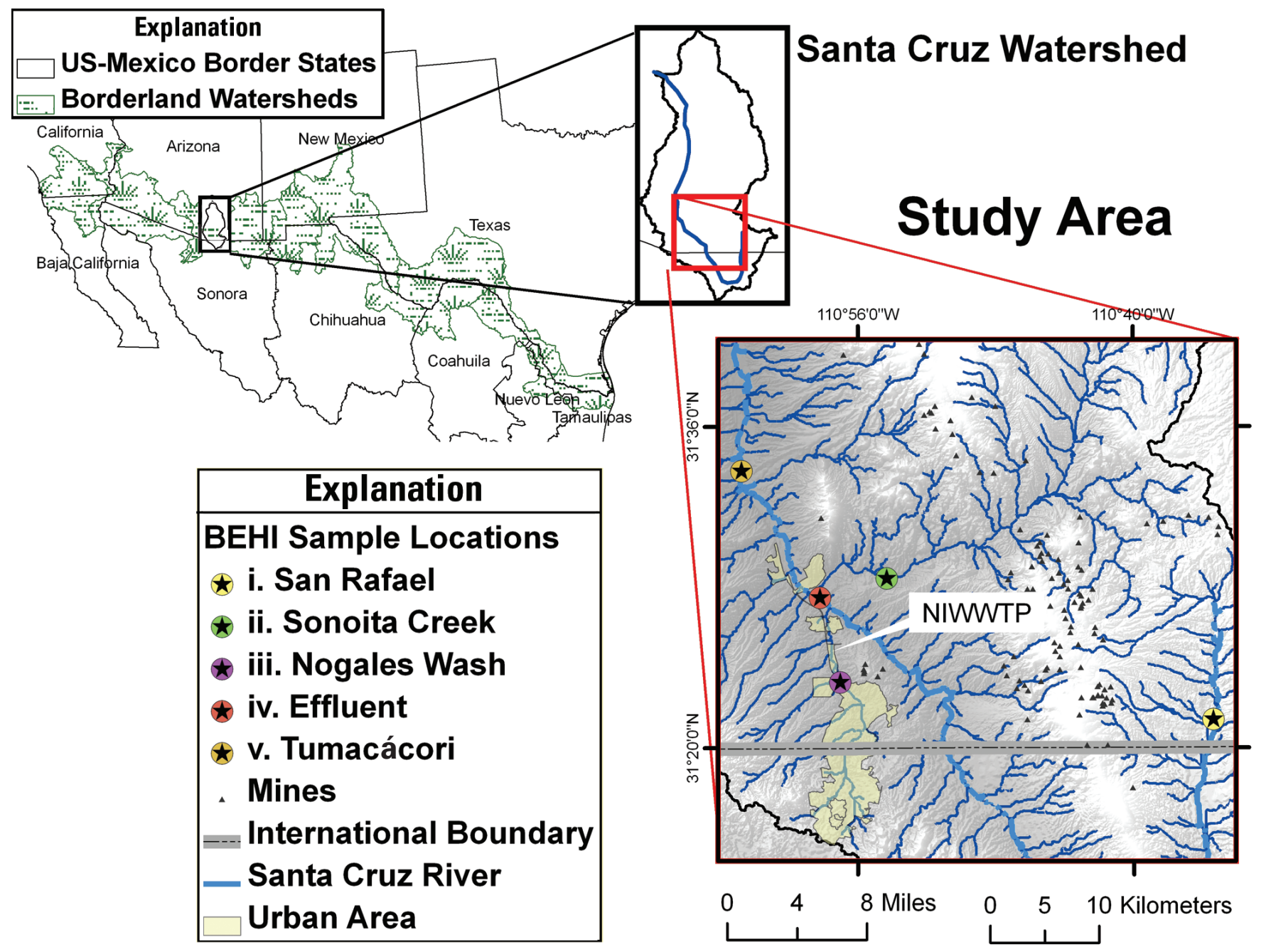

Figure 2. Map showing location of the Santa Cruz River Watershed at the Arizona-Sonora border and locations of sampling sites in the study area. NIWWTP, Nogales International Waste Water Treatment Plant.

Field samples are being obtained at sites that coincide with historical sampling programs of the U.S. Fish and Wildlife Service (King and others, 1999). Site locations (see fig. 2) include (i) the headwaters at San Rafael del la Zanja (which should be unaffected by downstream contaminant sources); (ii) the Sonoita Creek tributary, which passes through the abandoned mining district at Patagonia; (iii) the binational Nogales Wash tributary that flows through highly urbanized areas of Nogales, Sonora, and Nogales, Arizona; (iv) effluent downstream from the Nogales International Waste Water Treatment Plant (NIWWTP); and (v) the Santa Cruz River at Tumacácori, downstream of the confluence of these several branches. This experimental design allows USGS scientists to accurately determine contaminant contributions from the mining district and municipalities; it will also provide information on contaminant levels in water before entering and after exiting the NIWWTP.

Field data are being used in combination with the Soil and Water Assessment Tool (SWAT) to identify contributing areas, sources and transport modes of contaminants to track their movement in surface waters. SWAT is a watershed model that quantifies the impact of land management practices, and estimates of runoff and evapotranspiration from SWAT simulations will be used to modify boundary conditions in existing groundwater-flow models. The resulting improved understanding of the effects of human activities on aquifer dynamics and contaminant transport will enable the SWAT model to be used to identify critical subwatersheds where implementing management practices could be most effective to abate pollution. This USGS research in the Santa Cruz River Watershed will help determine the linkages between the condition of the physical environment and health issues in the borderlands.

\section{Reference Cited}

King, K.A., Zaun, B.J., and Velasco, A.L., 1997, Contaminants as a limiting factor of fish and wildlife populations in the Santa Cruz River, Arizona: U.S. Fish and Wildlife Service,

Phoenix, Ariz., 66 p.

For more information contact

Laura M. Norman,Inorman@usgs.gov; James Callegary, jcallega@usgs.gov;

Charles van Riper III, charles_van_riper@usgs.gov; and Floyd Gray, fgray@usgs.gov 